Supplement of Atmos. Chem. Phys. Discuss., 15, 35417-35484, 2015

http://www.atmos-chem-phys-discuss.net/15/35417/2015/

doi:10.5194/acpd-15-35417-2015-supplement

(C) Author(s) 2015. CC Attribution 3.0 License.

(c) (i)

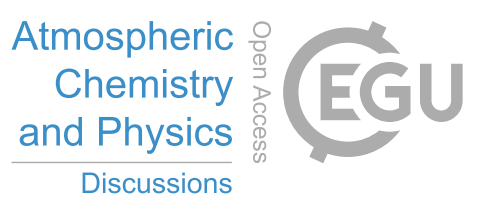

Supplement of

\title{
Validation of the Swiss methane emission inventory by atmospheric observations and inverse modelling
}

\section{S. Henne et al.}

Correspondence to: S. Henne (stephan.henne@empa.ch)

The copyright of individual parts of the supplement might differ from the CC-BY 3.0 licence. 


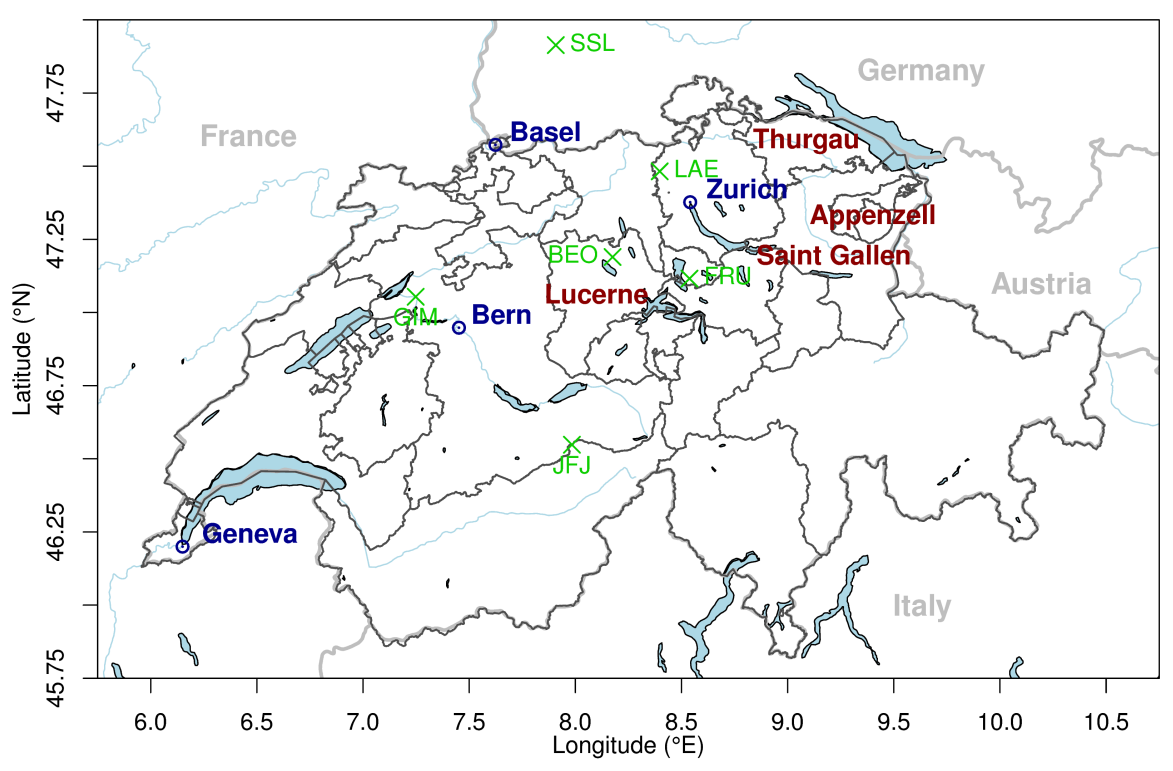

Fig. S1: Map of Switzerland illustrating the cantonal borders (gray), major cities (blue), observational sites (green), and cantons (red) mentioned in the text.

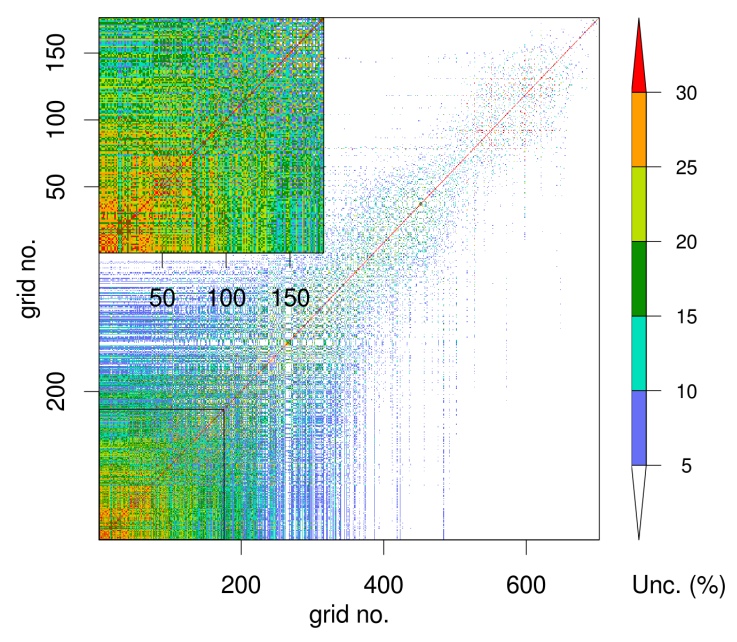

Fig. S2: Relative prior uncertainty covariance matrix of the emission fluxes, $\mathbf{B}^{\mathbf{E}}$, as used in the base inversion with low release height. Note that grid cells are ordered by size, the smallest cells having the smallest grid number. The subplot zooms in on the smallest grid cells for which large off diagonal elements were assigned. The large uncertainty seen for grid cells around number 600 results from assigning a larger relative uncertainty to grid cells with close to zero emissions. 
a)
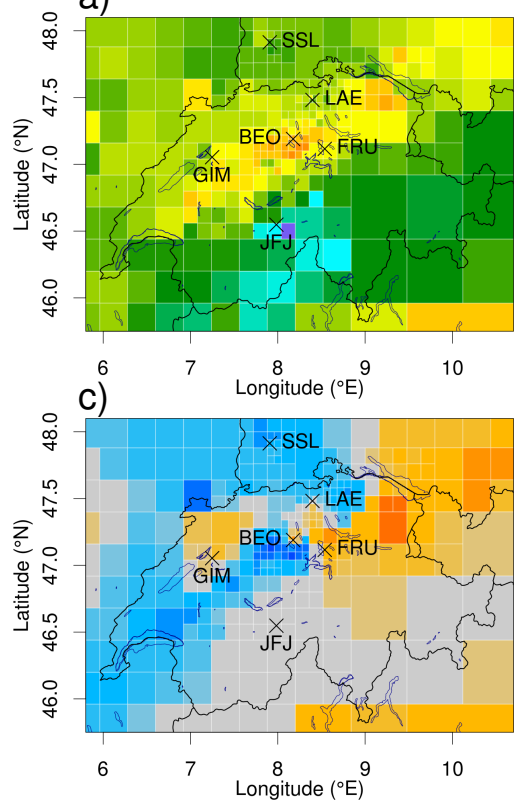

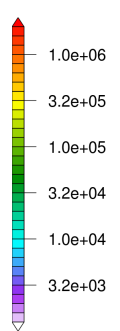

$\mathrm{e}\left(\mu \mathrm{g} \mathrm{s}^{-1} \mathrm{~km}^{-2}\right)$ b)

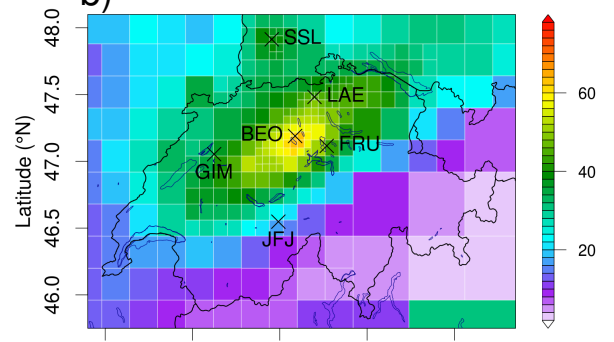

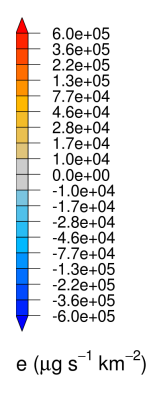

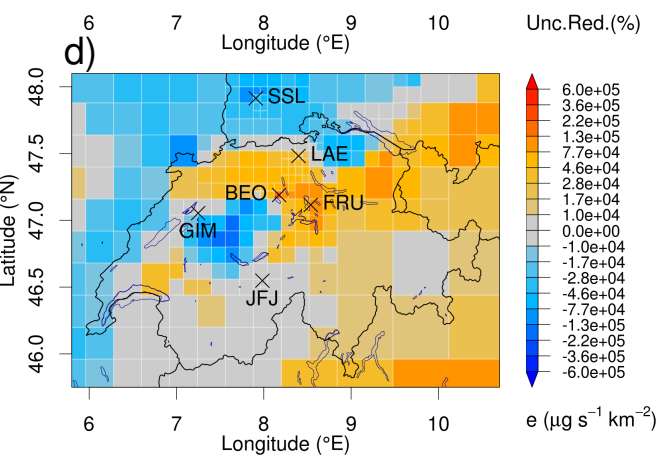

Fig. S3: (a) prior surface fluxes of $\mathrm{CH}_{4}$ and (b) posterior uncertainty reduction, absolute difference between posterior and prior emission fluxes for (c) low and (d) high particle release in the base inversion (B).

a)
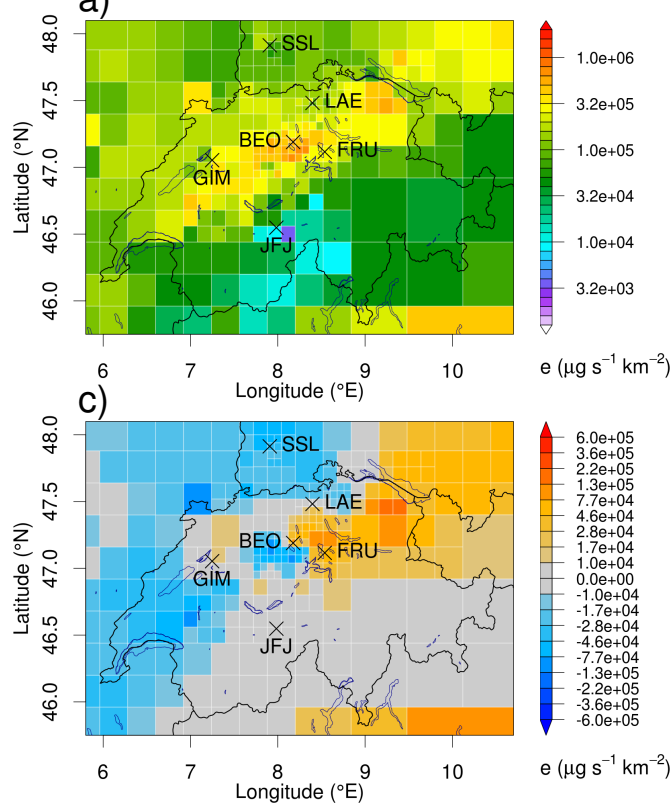

b)
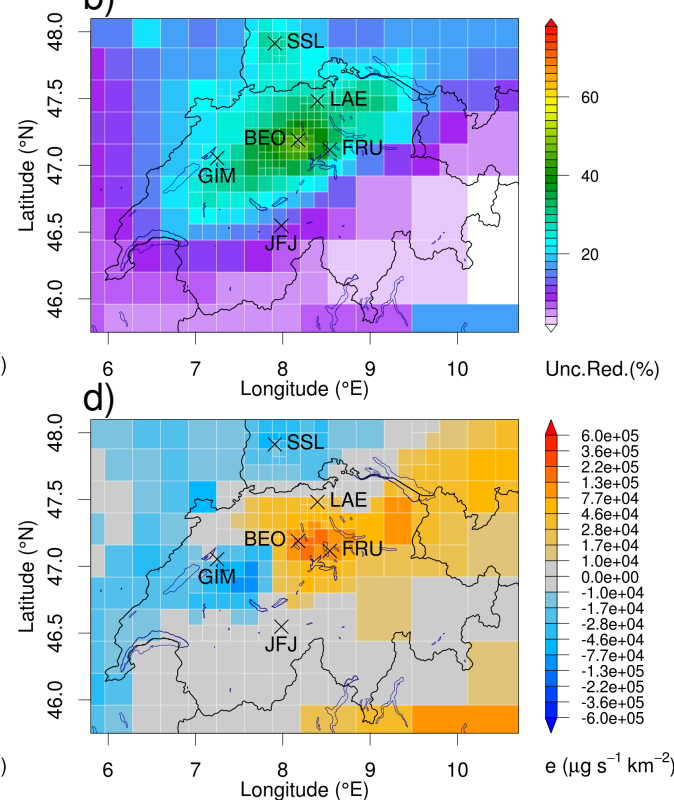

Fig. S4: (a) prior surface fluxes of $\mathrm{CH}_{4}$ and (b) posterior uncertainty reduction, absolute difference between posterior and prior emission fluxes for (c) low and (d) high particle release in the sensitivity inversion estimating flux by season $(\mathrm{S}-\mathrm{V})$. 
a)
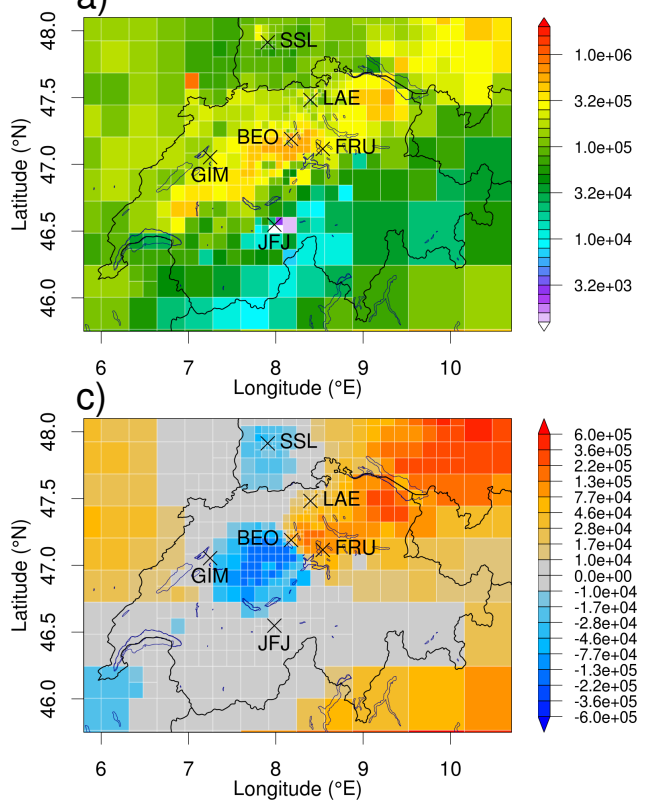

b)
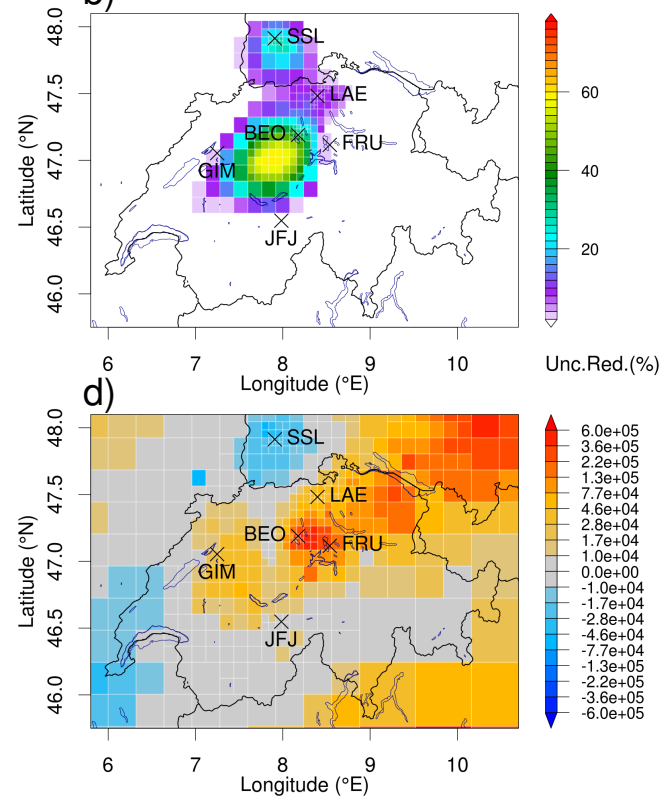

Fig. S5: (a) prior surface fluxes of $\mathrm{CH}_{4}$ and (b) posterior uncertainty reduction, absolute difference between posterior and prior emission fluxes for (c) low and (d) high particle release in the sensitivity inversion using the extended Kalman filter method (S-K).

a)
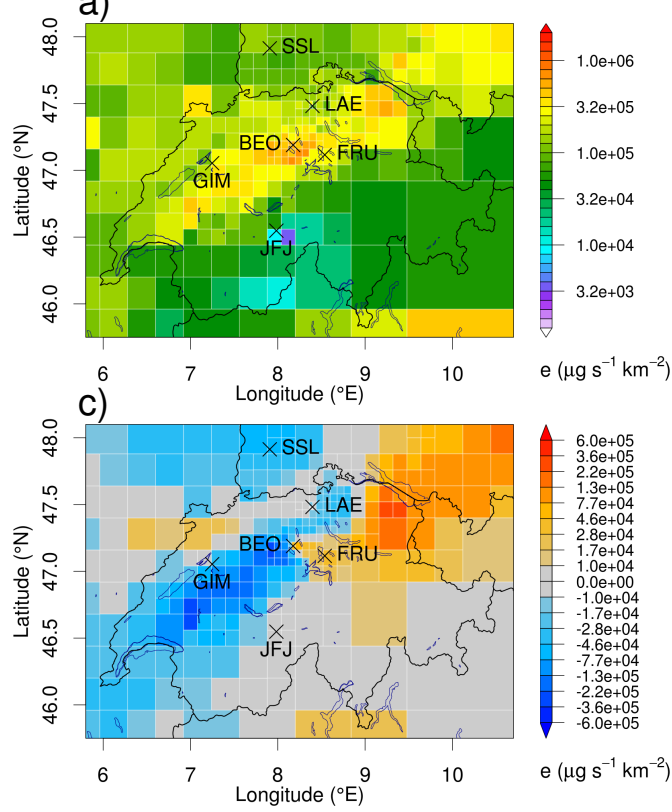

b)
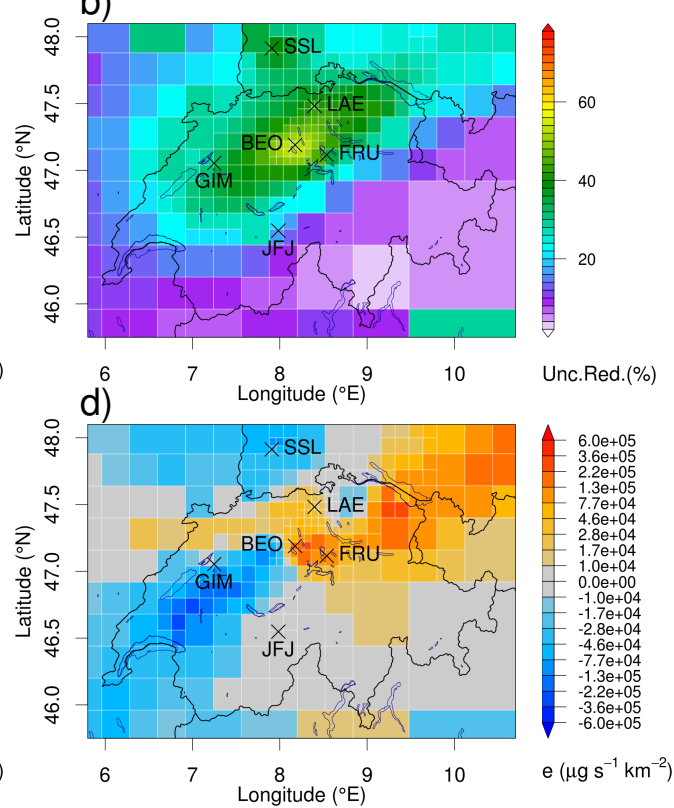

Fig. S6: (a) prior surface fluxes of $\mathrm{CH}_{4}$ and (b) posterior uncertainty reduction, absolute difference between posterior and prior emission fluxes for (c) low and (d) high particle release in the sensitivity inversion based on FLEXPART-ECMWF transport model (S-EC). 
a)
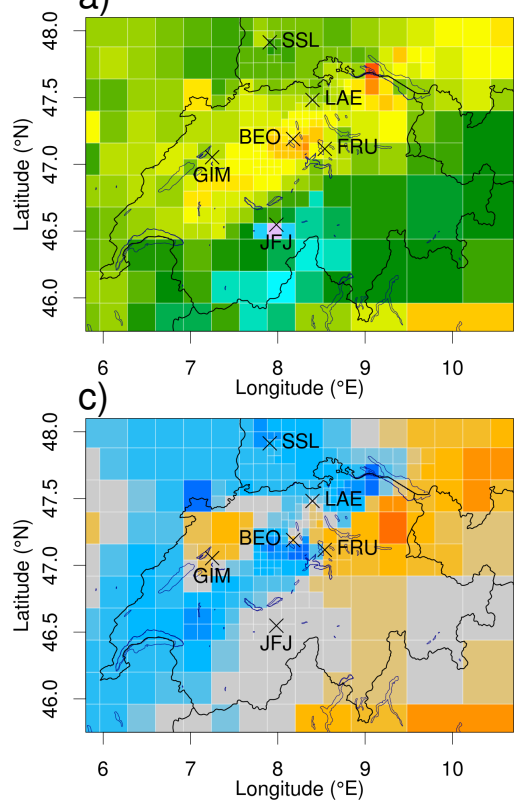

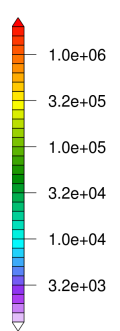

$\mathrm{e}\left(\mu \mathrm{g} \mathrm{s}^{-1} \mathrm{~km}^{-2}\right)$ b)

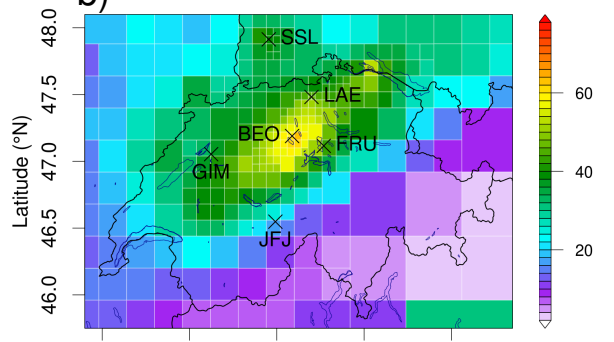

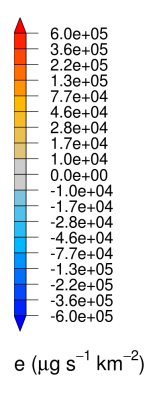

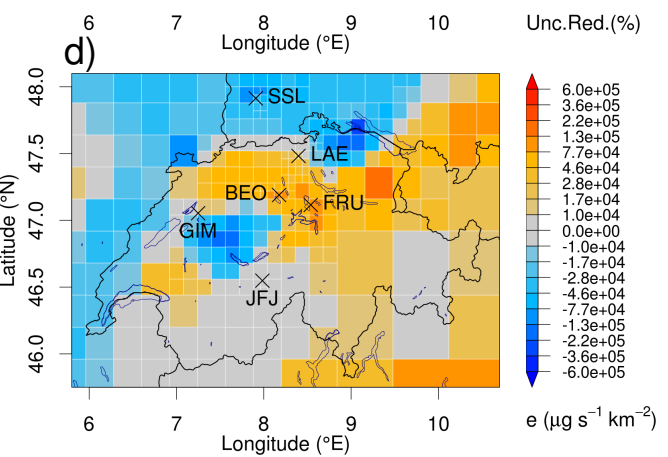

Fig. S7: (a) prior surface fluxes of $\mathrm{CH}_{4}$ and (b) posterior uncertainty reduction, absolute difference between posterior and prior emission fluxes for (c) low and (d) high particle release in the sensitivity inversion using prior emissions from TNO/MACC (S-T).

a)
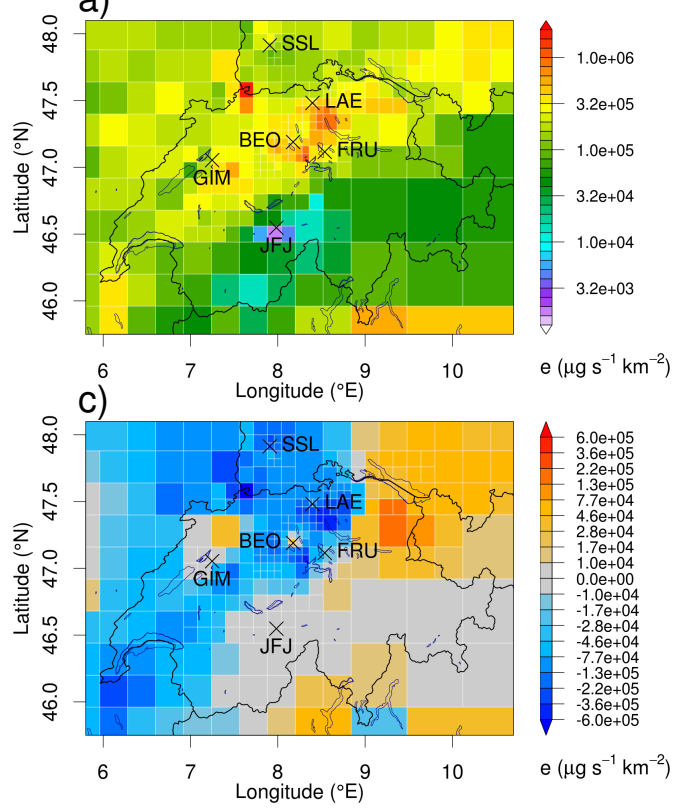

b)
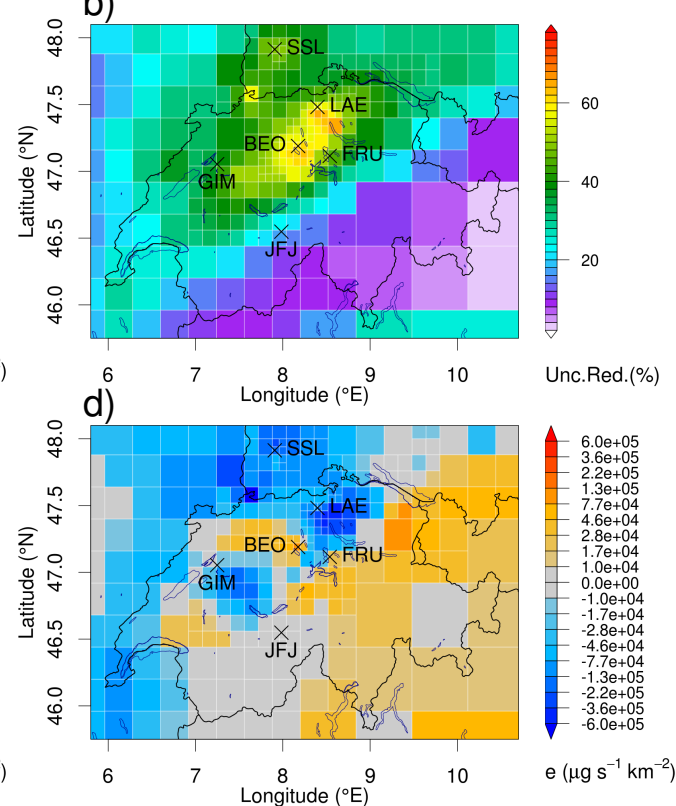

Fig. S8: (a) prior surface fluxes of $\mathrm{CH}_{4}$ and (b) posterior uncertainty reduction, absolute difference between posterior and prior emission fluxes for (c) low and (d) high particle release in the sensitivity inversion using prior emissions from EDGAR (S-E). 
a)

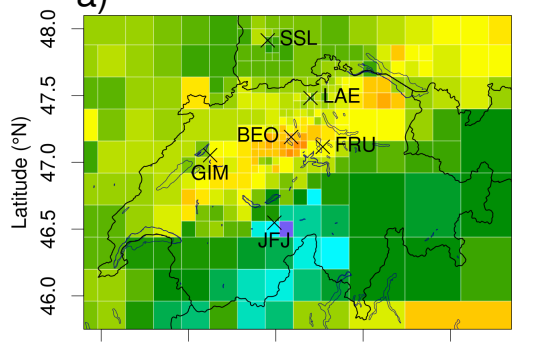

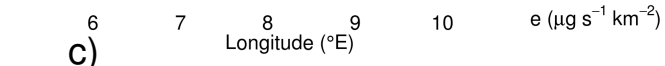
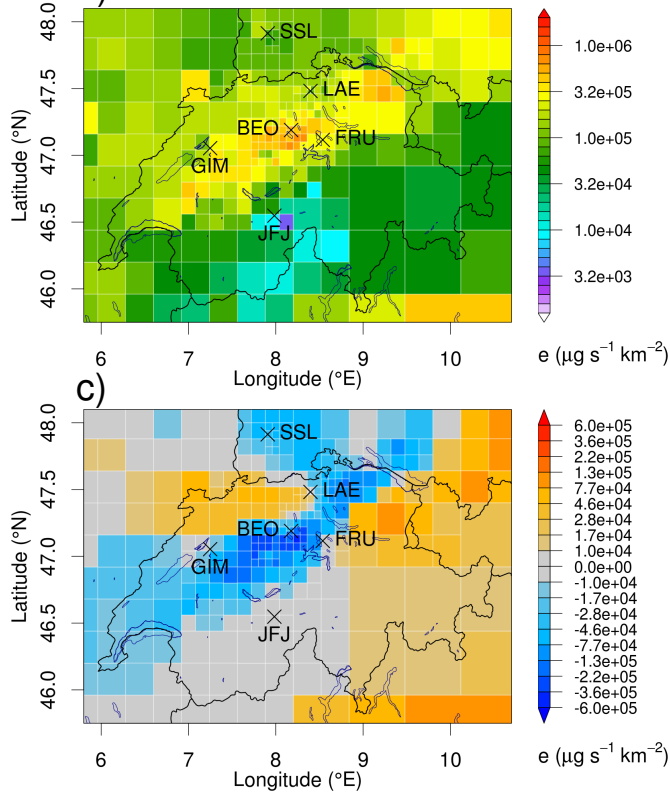

b)

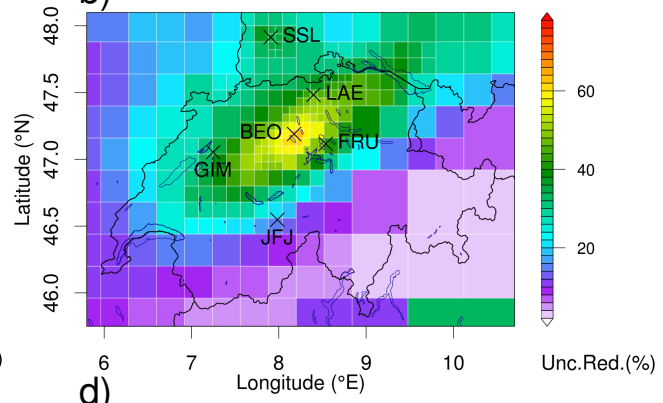

d) $\quad 7 \quad$ Longitude $\left({ }^{6} E\right)^{9}$

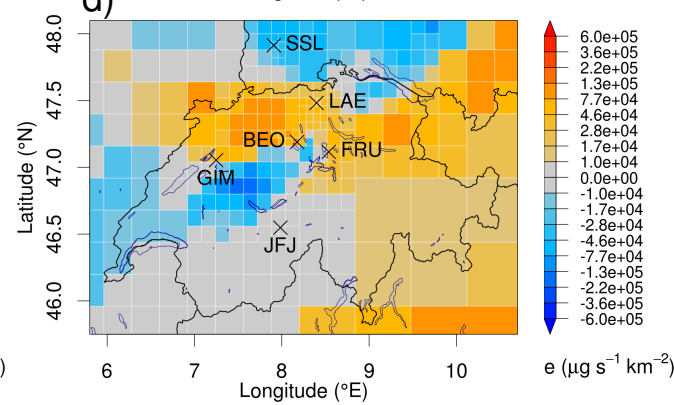

Fig. S9: (a) prior surface fluxes of $\mathrm{CH}_{4}$ and (b) posterior uncertainty reduction, absolute difference between posterior and prior emission fluxes for (c) low and (d) high particle release in the sensitivity inversion using model uncertainty as derived with method by Stohl et al. (2009) (S-S).

a)

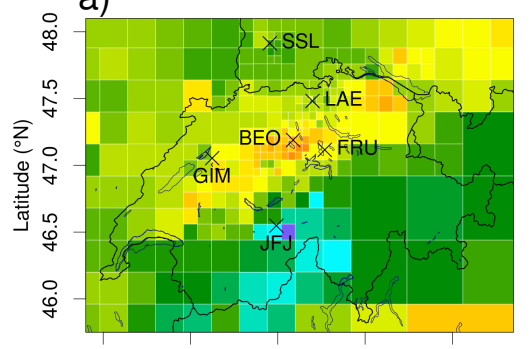

c)

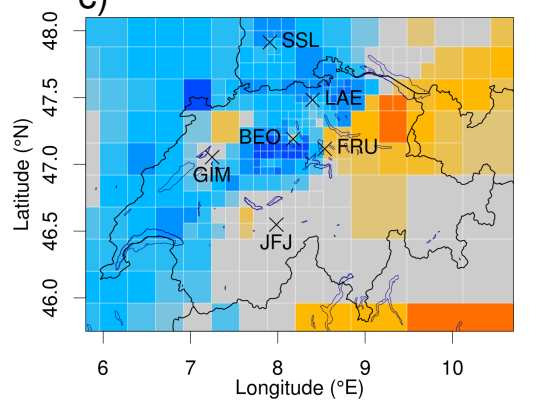

b)

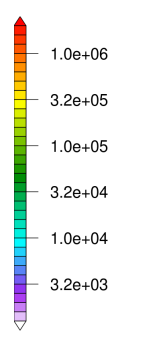

$\mathrm{e}\left(\mu \mathrm{g} \mathrm{s}^{-1} \mathrm{~km}^{-2}\right)$
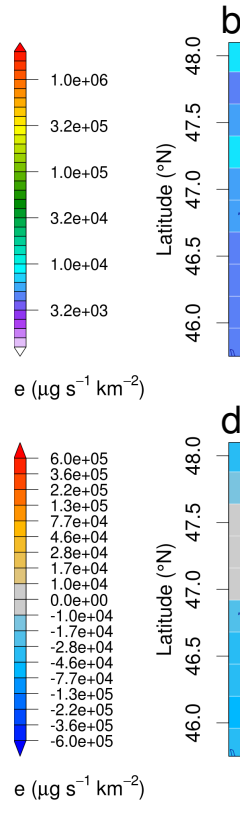

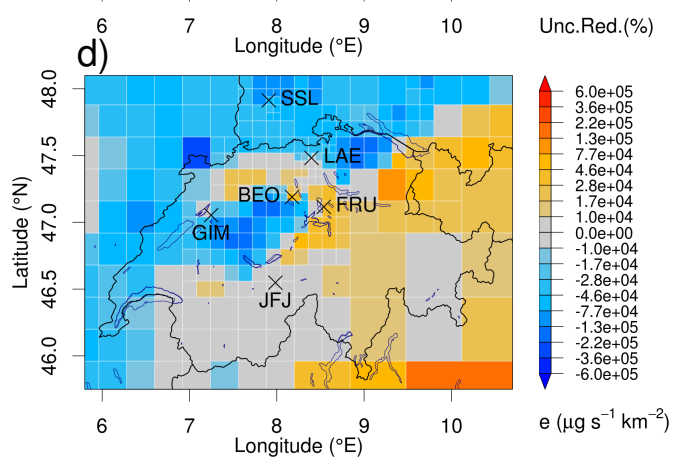

Fig. S10: (a) prior surface fluxes of $\mathrm{CH}_{4}$ and (b) posterior uncertainty reduction, absolute difference between posterior and prior emission fluxes for (c) low and (d) high particle release in the sensitivity inversion using covariance parameters as obtained the maximum likelihood optimisation (S-ML). 
a)
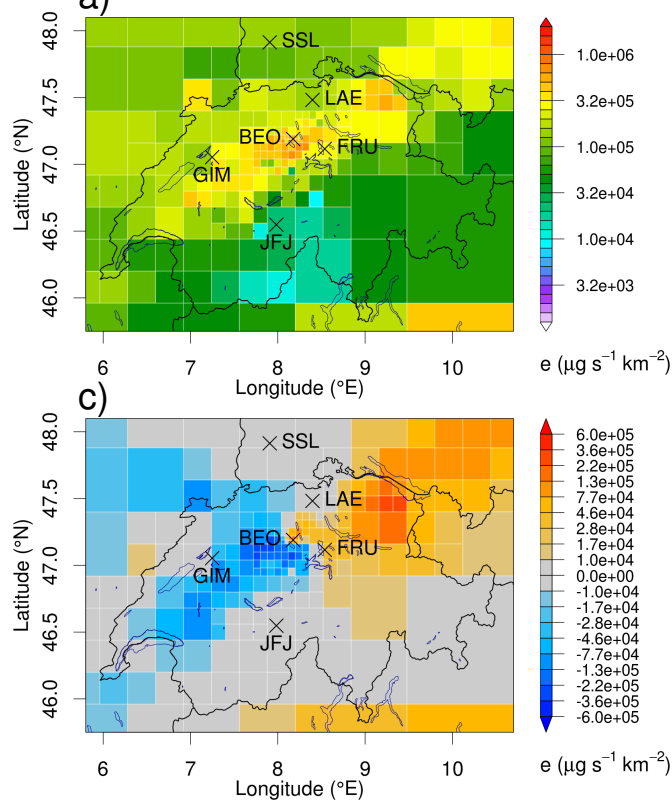

b)
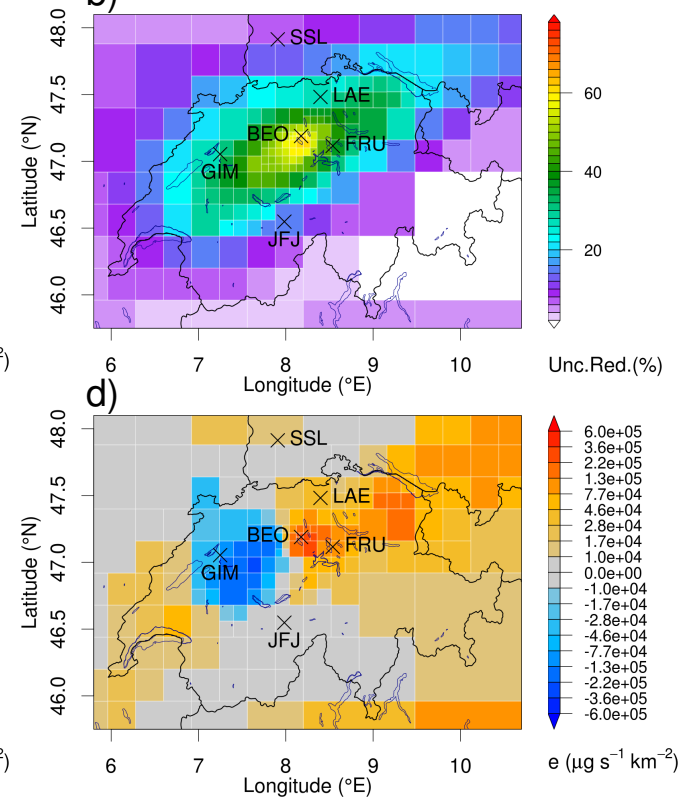

Fig. S11: (a) prior surface fluxes of $\mathrm{CH}_{4}$ and (b) posterior uncertainty reduction, absolute difference between posterior and prior emission fluxes for (c) low and (d) high particle release in the sensitivity inversion using only observations from BEO (S-O1).

a)
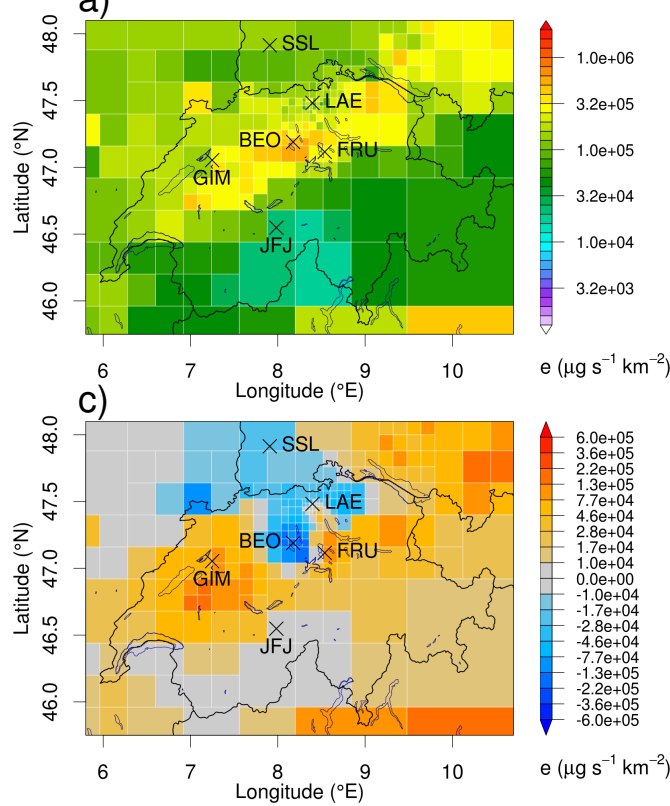

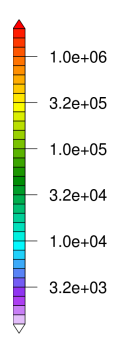

$\mathrm{e}\left(\mu \mathrm{g} \mathrm{s}^{-1} \mathrm{~km}^{-2}\right)$

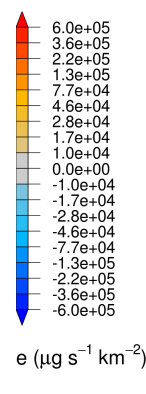

b)
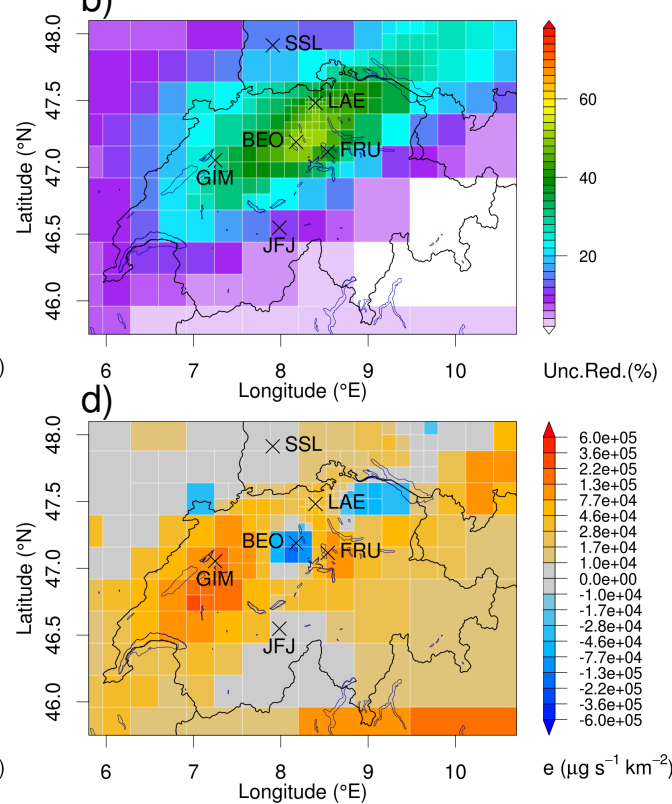

Fig. S12: (a) prior surface fluxes of $\mathrm{CH}_{4}$ and (b) posterior uncertainty reduction, absolute difference between posterior and prior emission fluxes for (c) low and (d) high particle release in the sensitivity inversion using only observations from LAE (S-O2). 
a)
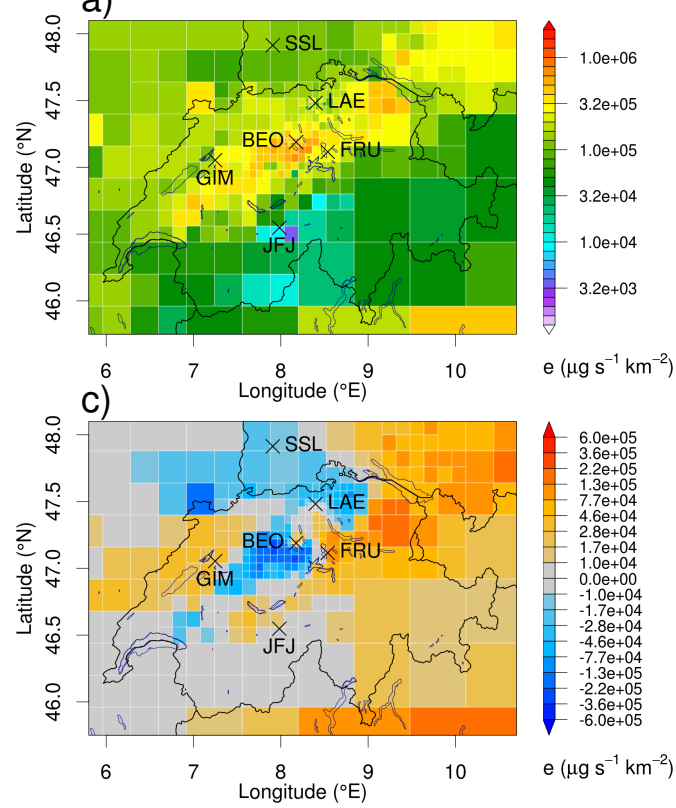

b)
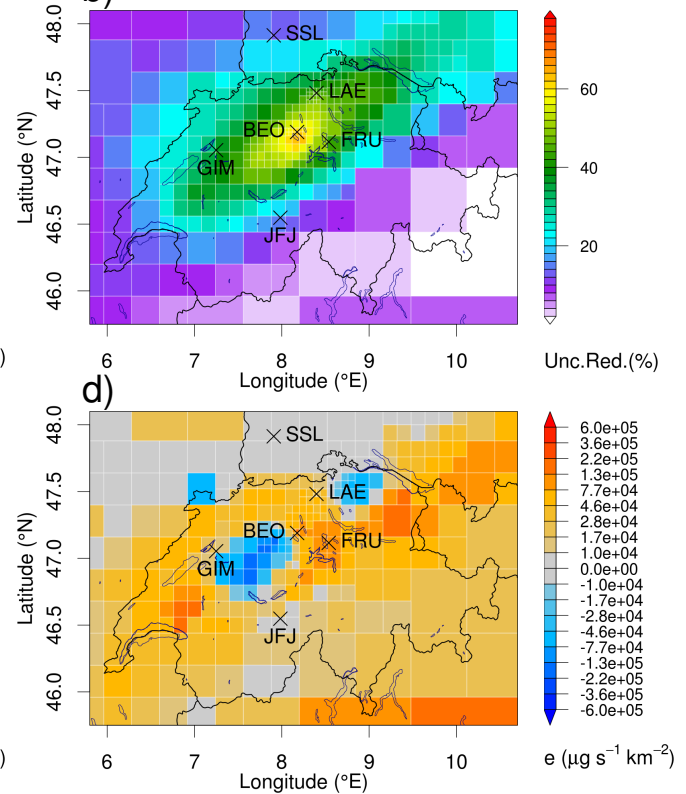

Fig. S13: (a) prior surface fluxes of $\mathrm{CH}_{4}$ and (b) posterior uncertainty reduction, absolute difference between posterior and prior emission fluxes for (c) low and (d) high particle release in the sensitivity inversion using only observations from BEO and LAE (S-O3).

a)
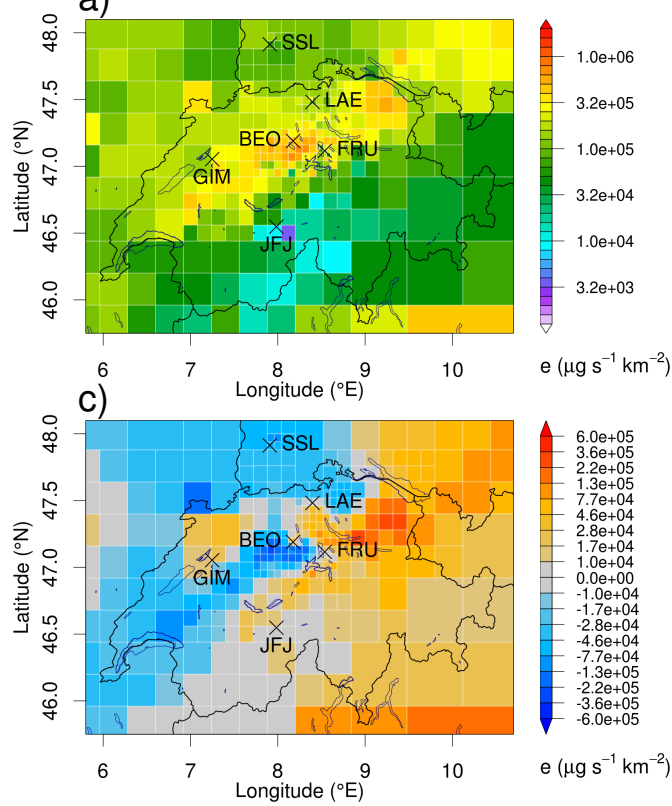

b)
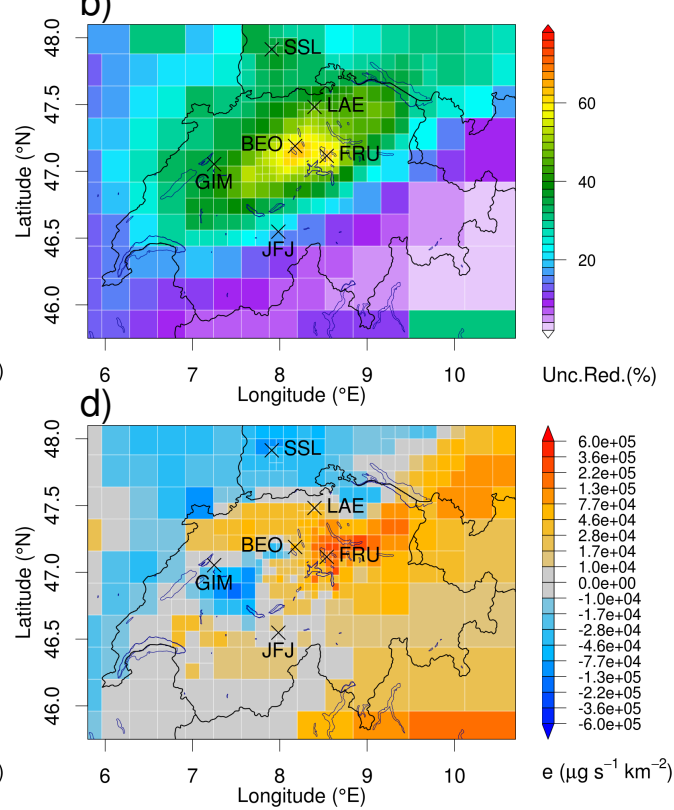

Fig. S14: (a) prior surface fluxes of $\mathrm{CH}_{4}$ and (b) posterior uncertainty reduction, absolute difference between posterior and prior emission fluxes for (c) low and (d) high particle release in the sensitivity inversion using observations from BEO, LAE, JFJ, SSL and FRU (S-O4). 
a)
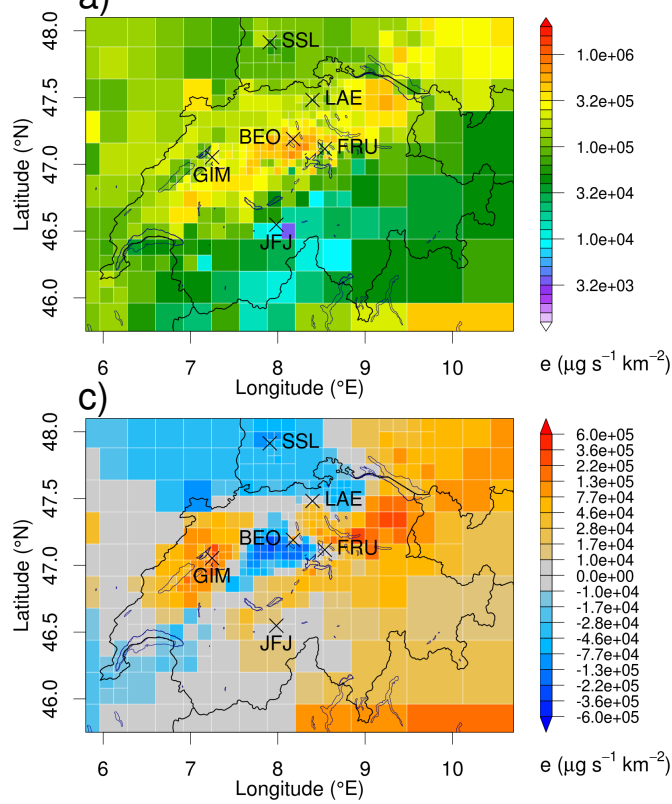

b)
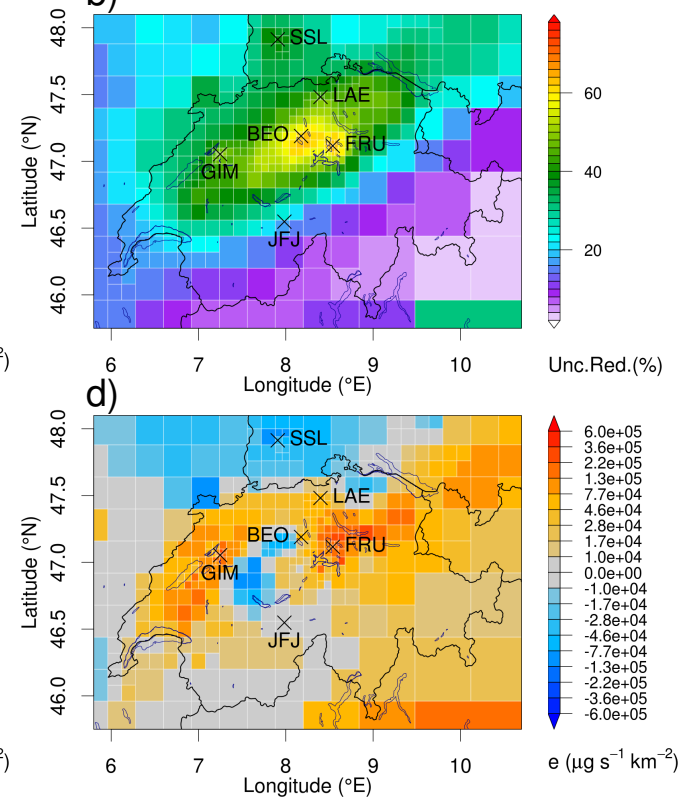

Fig. S15: (a) prior surface fluxes of $\mathrm{CH}_{4}$ and (b) posterior uncertainty reduction, absolute difference between posterior and prior emission fluxes for (c) low and (d) high particle release in the sensitivity inversion using observations from all six sites (S-O5).

a)
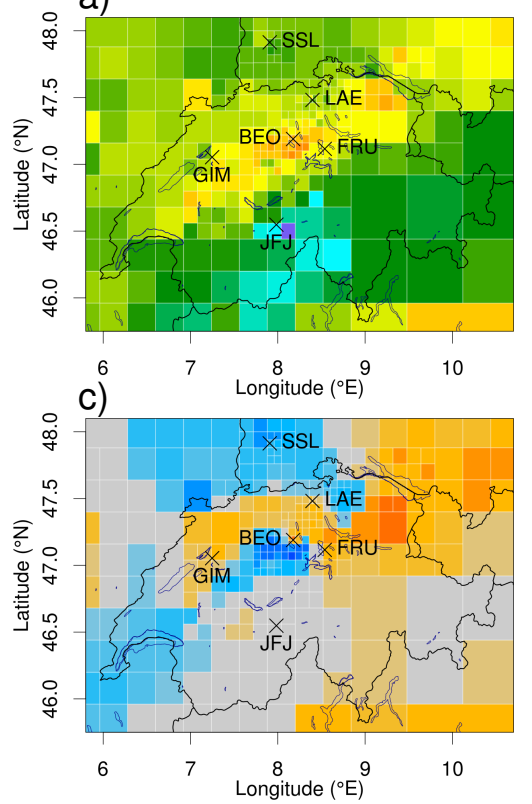

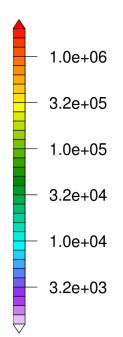

$\mathrm{e}\left(\mu \mathrm{g} \mathrm{s}^{-1} \mathrm{~km}^{-2}\right)$

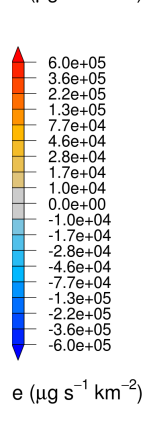

b)
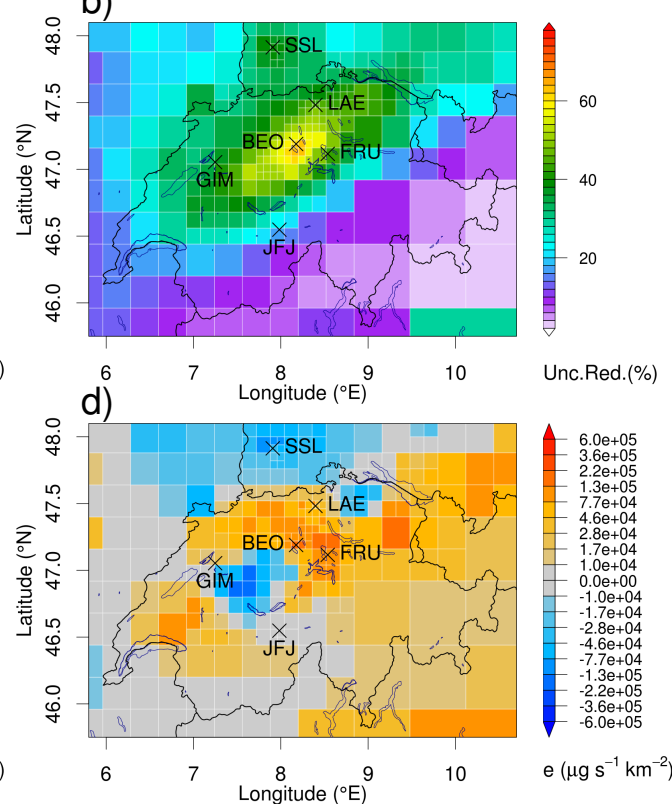

Fig. S16: (a) prior surface fluxes of $\mathrm{CH}_{4}$ and (b) posterior uncertainty reduction, absolute difference between posterior and prior emission fluxes for (c) low and (d) high particle release in the sensitivity inversion using west-east gradient in the baseline mole fractions (S-B1). 
a)
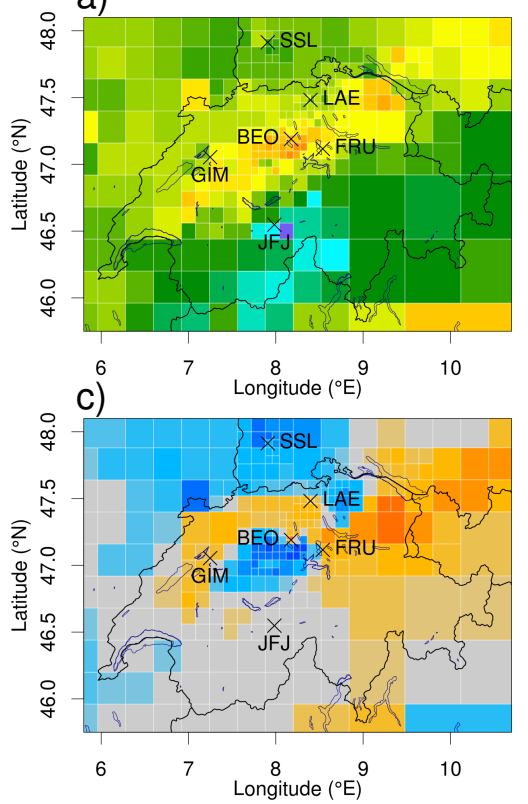

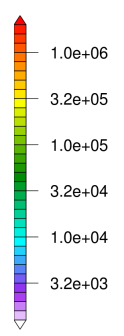

$\mathrm{e}\left(\mu \mathrm{g} \mathrm{s}^{-1} \mathrm{~km}^{-2}\right)$

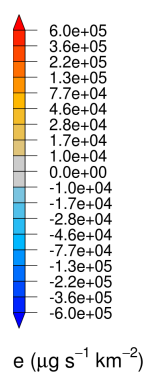

b)
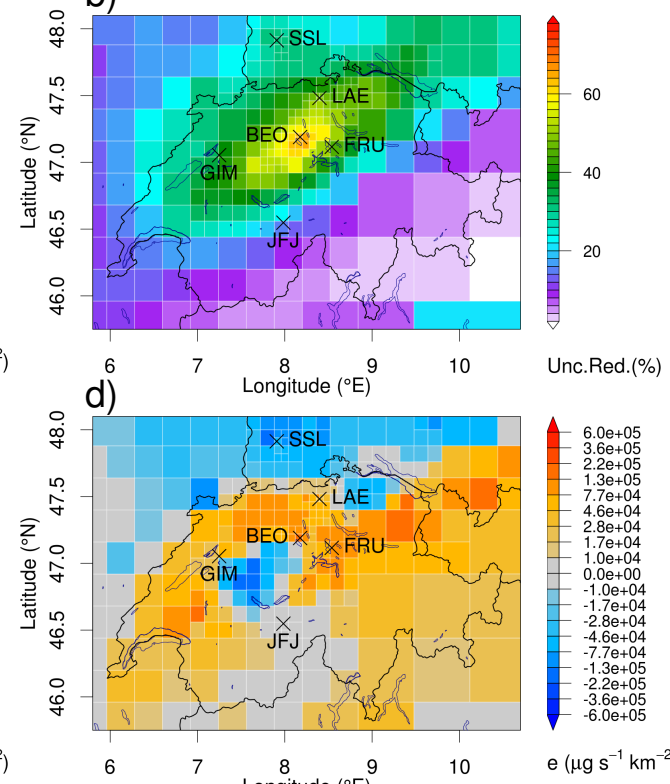

d)

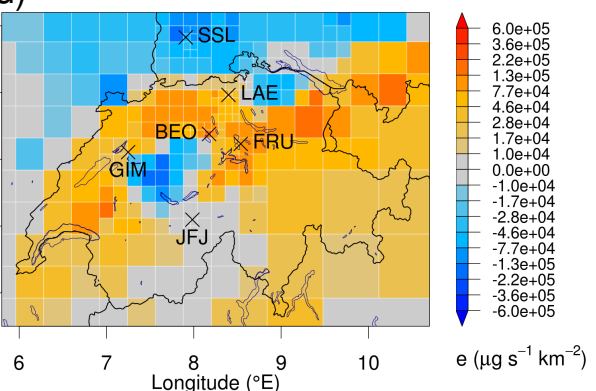

Fig. S17: (a) prior surface fluxes of $\mathrm{CH}_{4}$ and (b) posterior uncertainty reduction, absolute difference between posterior and prior emission fluxes for (c) low and (d) high particle release in the sensitivity inversion using gridded baseline mole fractions (S-B2).

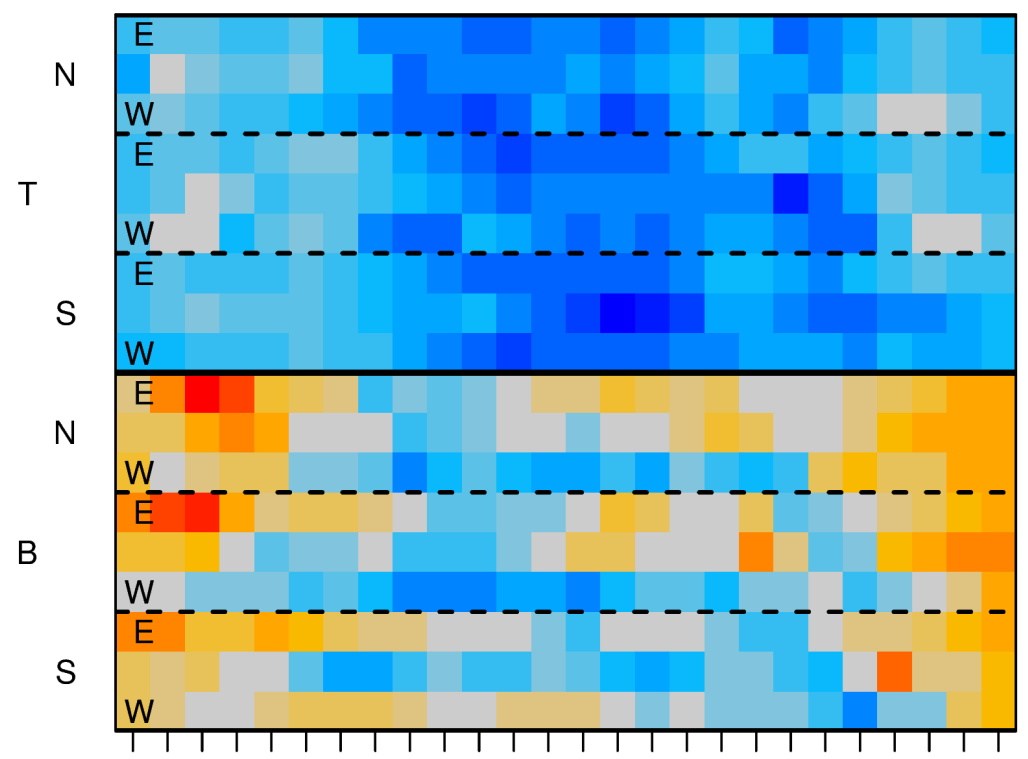

Mar 13 Apr 13 Jun 13 Aug 13 Oct 13 Dec 13 Feb 14

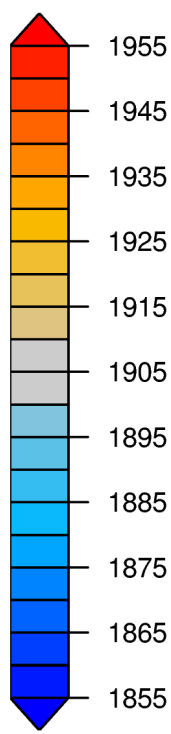

$\mathrm{CH} 4(\mathrm{ppb})$

Fig. S18: Temporal evolution of posterior baseline mole fractions for all grid boxes in baseline grid as estimated in low S-B2. Grid boxes are ordered from top to bottom, north to south and east to west, as indicated on the y-axis. 


\section{References}

Stohl, A., Seibert, P., Arduini, J., Eckhardt, S., Fraser, P., Greally, B. R., Lunder, C., Maione, M., Mühle, J., O’Doherty, S., Prinn, R. G., Reimann, S., Saito, T., Schmidbauer, N., Simmonds, P. G., Vollmer, M. K., Weiss, R. F., and Yokouchi, Y.: An analytical inversion method for determining regional and global emissions of greenhouse gases: Sensitivity studies and application to halocarbons, Atmos. Chem. Phys., 9, 1597-1620, doi:10.5194/acp-9-1597-2009, 2009. 